Arq. Bras. Med. Vet. Zootec., v.67, n.1, p.80-88, 2015

\title{
Aspectos do uso territorial por onça parda (Puma concolor), através de monitoramento via satélite, na região do Parque Estadual da Serra do Brigadeiro, MG
}

[Aspects of territorial use of the Cougar (Puma concolor), by satelite monitoring, in the Parque Estadual da Serra do Brigadeiro, $M G]$

\author{
T.A.R. Paula ${ }^{1}$, G.R. Araujo ${ }^{1}$, T. Deco-Souza ${ }^{2}$, A.C. Csermak Jr. ${ }^{1}$, L.C.F. Bergo ${ }^{1}$, J.E. Mantovani ${ }^{3}$, \\ L.C. Silva ${ }^{1}$, R.C.F. Magaldi ${ }^{1}$, A.S. Trece ${ }^{1}$, J.P. Caliman ${ }^{1}$ \\ ${ }^{1}$ Universidade Federal de Viçosa - UFV - Viçosa, MG \\ ${ }^{2}$ Universidade Federal do Mato Grosso do Sul - Campo Grande, MS \\ ${ }^{3}$ Instituto Nacional de Pesquisas Espaciais - Natal, RN
}

\begin{abstract}
RESUMO
Objetivou-se com o presente estudo monitorar o comportamento do uso territorial de um macho de onça parda, capturado no Parque Estadual da Serra do Brigadeiro (PESB), por meio da telemetria, usando colar de GPS via Satélite Globalstar. O monitoramento de doze meses resultou na transmissão via satélite de 328 localizações, as quais sugerem que a área utilizada por esse felino seja de aproximadamente $610 \mathrm{~km}^{2}$, sendo esta a maior área já descrita para a espécie. Foi possível observar que apenas $20 \%$ das localizações ocorreram dentro da área do PESB. O comportamento territorial observado neste trabalho mostra a vulnerabilidade do animal a ações antrópicas, como a caça, atropelamentos e o contato com patógenos entre animais silvestres e domésticos. Observou-se também que duas rodovias configuram barreiras artificiais para o deslocamento do animal, possivelmente impedindo o fluxo gênico entre o PESB e dois outros importantes parques. Com os dados levantados é possível a sugestão de ações de manejo, como a criação de uma conectividade efetiva entre o PESB, o Parque Estadual do Rio Doce e o Parque Nacional do Caparaó, o que poderia contribuir para o intercâmbio genético entre as populações e, dessa forma, favorecer a conservação não somente da onça parda.
\end{abstract}

Palavras-chave: grande felino, telemetria, área de vida, Mata Atlântica

\begin{abstract}
We aimed to study the territorial behavior of a male cougar, captured in the Parque Estadual da Serra do Brigadeiro (PESB), using a GPS collar and the Globalstar Satellite. Monitoring the animal for nine months we obtained 328 locations. The data suggest that the area used by this feline is approximately $610 \mathrm{~km}^{2}$, the largest area described for this specie. It was also possible to observe that only $20 \%$ of the locations of the animal occurred within the PESB area. The territorial behavior observed in this study shows the vulnerability of the animal to human activities such as hunting, road kill and contact with pathogens from domestic animals. It was also observed that two roads constitute artificial barriers for animal movement, possibly preventing gene flow between the PESB and two other parks. The creation of an effective connectivity between the PESB, the Parque Estadual do Rio Doce and the Parque Nacional do Caparaó is critical to ensure genetic exchange between the animal populations and thereby promote their conservation.
\end{abstract}

Keywords: big cat, telemetry, living area, Atlantic Forest

\section{INTRODUÇÃO}

A Mata Atlântica possui a maior parte de seus remanescentes florestais em áreas intensamente cultivadas, na forma de pequenos fragmentos, altamente perturbados, pouco estudados e pouco protegidos (Viana e Tabanez, 1996). De acordo com o atlas da Biodiversidade em Minas Gerais, na Mata Atlântica encontrada no estado situamse áreas consideradas de importância biológica especial, por serem áreas com ocorrência de espécies restritas a ambiente único no estado, como o Parque Estadual da Serra do Brigadeiro (Drummond et al., 2005). Nesse parque

Recebido em 10 de setembro de 2013

Aceito em 10 de junho de 2014

E-mail: tarcizio@ufv.br 
encontra-se uma grande diversidade de espécies de mamíferos, muitas delas ameaçadas de extinção, como a onça parda e o muriqui (Biodiversitas, 2007).

Grandes felinos tendem a ocupar grandes áreas de vida, e com isso tornam-se extremamente vulneráveis à redução e fragmentação de áreas florestais (Sutherland, 2000; Pinto et al., 2006). Quando uma população é isolada geograficamente e fica susceptível à uniformidade genética, ocorre a redução da sua habilidade de se adaptar às mudanças ambientais e vários fatores se aliam para desencadear o processo de extinção (Galetti et al., 2003). Entre esses fatores estão a diminuição da fertilidade, elevação da mortalidade infanto-juvenil e maior susceptibilidade a doenças (Wildt et al., 1987; Eizirik et al., 2001). Ao mesmo tempo, muitas dessas espécies, como a onça parda, são "espécies-chave" para processos ecológicos, pois a sua escassez ou ausência podem causar danos irreversíveis ao ecossistema onde ocorrem (Caughley e Sinclair, 1994). No entanto, sabe-se pouco sobre os requerimentos de área de grandes felinos neotropicais, dado à dificuldade em estudá-los em condições naturais.

Nesse sentido, ferramentas de estudo como a telemetria são de grande importância para o entendimento do comportamento territorial dessas espécies, uma vez que permitem o acompanhamento de sua movimentação à distância. A telemetria por GPS (Global Positioning System) torna bem mais eficiente a aquisição dos dados de localização em relação à técnica de triangulação por antena VHS, e tem sido especialmente empregada para espécies que utilizam grandes áreas, como a onça pintada (Panthera onca) e o lobo-guará (Chrysocyon brachyurus) (Soisalo e Cavalcanti, 2006; Bandeira de Melo, 2007). Essa técnica busca, em geral, elucidar padrões de movimentação, territorialidade e utilização de recursos, bem como avaliar parâmetros demográficos, tais como densidade, sobrevivência e dispersão de uma determinada espécie (Jacob e Rudran, 2003; Soisalo e Cavalcanti, 2006), ou ainda obter o padrão de distribuição espacial dos animais, informação de difícil obtensão por outras técnicas (Scoss et al., 2004). A logística de campo exigida pela tecnologia GPS é mais simples em função da forma de recolhimento dos dados, os quais podem ser recolhidos diretamente da coleira, quando esta é liberada do animal, por download remoto, com equipamento específico, ou ainda por recepção via satélite em tempo real. Esta última sendo a metodologia considerada ideal por oferecer a maior comodidade e menor interferência ao animal, porém com custo mais elevado.

A onça parda é o maior carnívoro encontrado no PESB (Silva, 2013) e, apesar da reconhecida importância dessa espécie para o ecossistema, não há estudos na área sobre o seu comportamento de uso territorial, dado este extremamente importante para subsídio de ações de manejo conservacionista. Nesse contexto, objetivou-se monitorar o comportamento de uso territorial de um macho de onça parda, capturado no PESB, por meio da telemetria, usando colar de GPS via Satélite Globasitar.

\section{MATERIAL E MÉTODOS}

O projeto foi devidamente autorizado pelo Instituto Chico Mendes (Licença número: 19956), pela Diretoria de Biodiversidade Gerência de Projetos e Pesquisas do Instituto Estadual de Floresta de Minas Gerais (Licença número: 57/10 II), Comissão de ética para o uso de animais CEUA-UFV, sendo registrado na Universidade Federal de Viçosa (Processo: 20457358760).

O Parque Estadual da Serra do Brigadeiro (PESB) localiza-se na Zona da Mata Mineira (Minas Gerais. Brasil), inserido nos municípios de Araponga, Fervedouro, Miradouro, Ervália, Sericita, Pedra Bonita, Muriaé e Divino (IEF, 2012) (Fig. 1). Possui uma área de 14.984 ha, entre os meridianos $42^{\circ} 20^{\prime}$ e $42^{\circ} 40^{\prime} \mathrm{S}$, e os paralelos 20 $20^{\prime}$ e $21^{\circ} 00^{\prime} \mathrm{W}$ (Moreira, 2005). Localiza-se em uma elevação da Serra da Mantiqueira, com elevações variando entre 1.000 e $2.000 \mathrm{~m}$ de altitude, com vales profundos e pequenos planaltos, exercendo importante influência nas características climáticas do parque (Carvalho, 2000). O regime pluviométrico do PESB é caracterizado por um período chuvoso durante os meses de novembro a março, que também é o mais quente, e por um período mais seco, de abril a setembro, o trimestre de junho, julho e agosto é o mais frio (Moreira, 2005). 


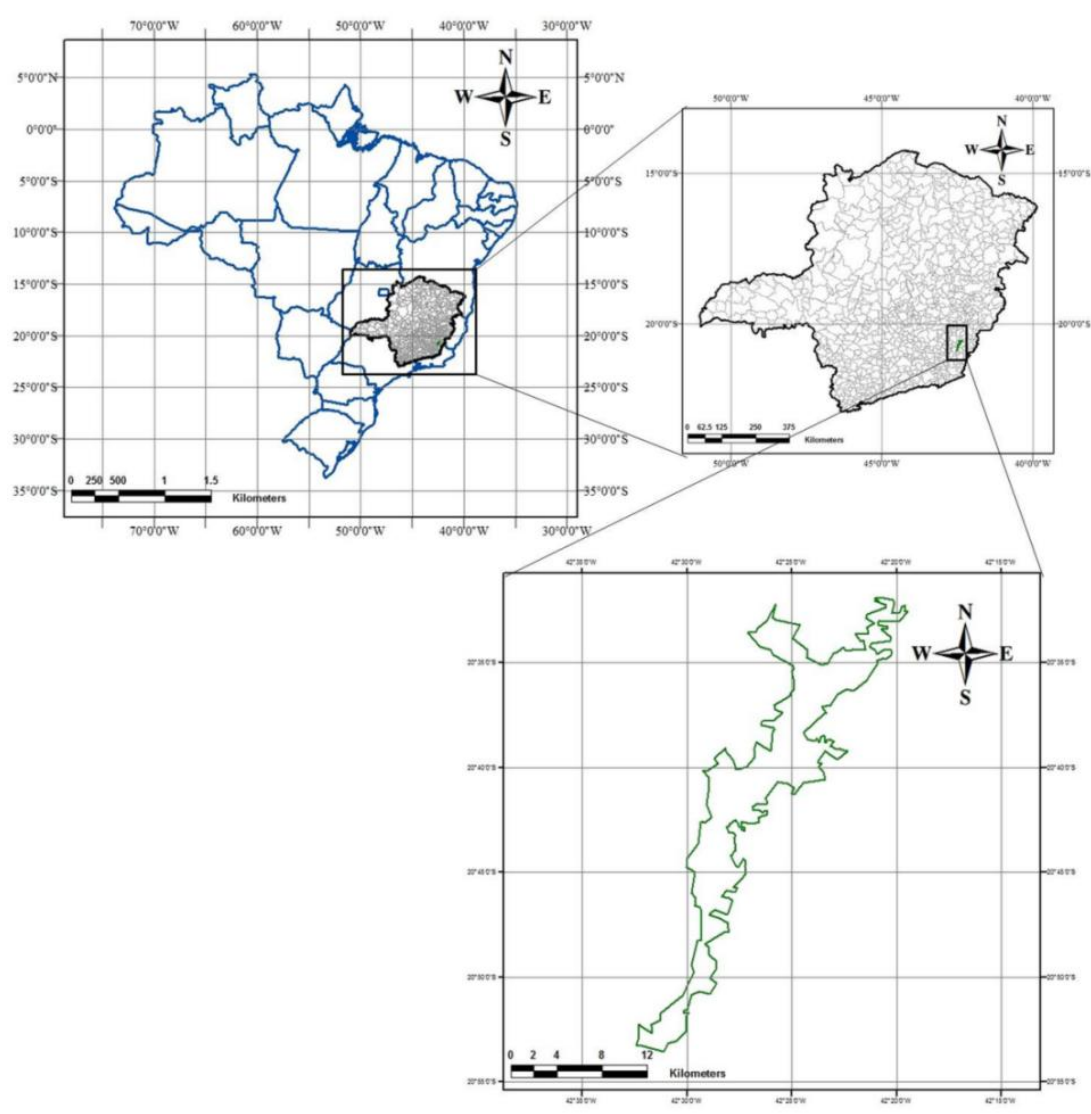

Figura 1. Visualização do Mapa do Brasil destacando o Estado de Minas Gerais e a localização do Parque Estadual da Serra do Brigadeiro, Zona da Mata, MG.

No dia 3 de setembro de 2012 foi capturado no PESB um macho adulto de onça parda, pesando $45 \mathrm{~kg}$ e em bom estado de saúde. O espécime foi considerado apto para o monitoramento e então aparelhado com uma coleira contendo equipamento de posicionamento global (GPS) e transmissor via satélite Globalstar.

Para a captura da onça parda foi usada a metodologia de armadilhamento de laço, com a utilização de 15 armadilhas. Essa metodologia consiste na utilização de laços de cabo de aço ancorados no solo, dotados de mecanismo de braço do tipo catapulta com mola e gatilhos de disparo por pressão. Os laços foram armadilhados em trilhas onde foi confirmada, através de estudo prévio por armadilhamento fotográfico (Silva, 2013), sua utilização por onças pardas. A fim de evitar danos ao animal, foram conectados, aos laços, transmissores de VHF que permitiam o monitoramento a distância do momento exato da captura, permitindo uma intervenção rápida. $\mathrm{O}$ animal capturado foi anestesiado utilizando-se o seguinte protocolo: contenção e indução anestésica com a associação de quetamina (10 a $20 \mathrm{mg} / \mathrm{kg}$ ) com xilazina (1 a $2 \mathrm{mg} / \mathrm{kg}$ ) em dardo anestésico, por via intramuscular, com o auxílio de rifle de $\mathrm{CO}_{2}$ e manutenção anestésica com o uso de gás Isoflurano por meio de aparelho de anestesia inalatória. Após a contenção química, o animal foi avaliado clinicamente, pesado e teve a faixa etária estimada em função do estado geral dos dentes. Após constatar que o animal era adulto, foi colocada nele uma coleira de GPS via satélite Globalstar (GlobalStar Track S, Loteck). O animal foi monitorado quanto aos parâmetros vitais por um médico veterinário utilizando um monitor multiparâmetro, durante todo o procedimento de manipulação. Cuidado especial foi tomado na fixação do colar, com uma folga suficiente para garantir o máximo possível de conforto sem permitir ao indivíduo desvencilharse do mesmo. A coleira, além do GPS, possui 
ainda transmissor de VHF e sistema de liberação automática da coleira (drop off), sendo programada para armazenar 9 localizações geográficas diárias e enviar, via satélite, as duas últimas localizações para um banco de dados online. Junto com as localizações geográficas também são enviadas informações de altitude e temperatura do ambiente.

As localizações armazenadas no banco de dados on-line foram utilizadas em análise do comportamento de uso da área de vida: total, durante a estação seca, durante a estação chuvosa, quanto ao uso da área do PESB e do entorno, padrões de deslocamentos e identificação de pontos de maior suscetibilidade a conflitos. As análises foram realizadas no software de geoprocessamento ArcGis 10.1 (ESRI,

http://www.esri.com/software/arcgis/index.html), com a utilização de imagens de satélite do Google Earth e mapas disponíveis do IBGE. Também foi produzido mapa de pontos (point maps) referentes às localizações e conversão do mesmo em mapa de polígonos (polygon map). Os dados foram ainda convertidos para o formato raster para a utilização das ferramentas de cálculo de área. A área de uso desse felino foi obtida através do cálculo do Mínimo Polígono Convexo (MPC), utilizando a ferramenta Minimum Bounding Geometry (ArcGis 10.1).

\section{RESULTADOS E DISCUSSÃO}

No período de 3 de setembro de 2012 até 15 de agosto de 2013, foram recebidos via satélite 328 pontos de coordenadas geográficas, distribuídos ao longo do período conforme sumarizados na Figura 2. A comunicação entre o radiocolar e o satélite é dependente de condições topográficas e climáticas específicas, assim, em muitas situações, em especial nos meses de fevereiro, julho e agosto, não foi possível a obtensão da maioria das coordenadas geográficas, porém houve uma distribuição representativa ao longo de todos os meses do ano.

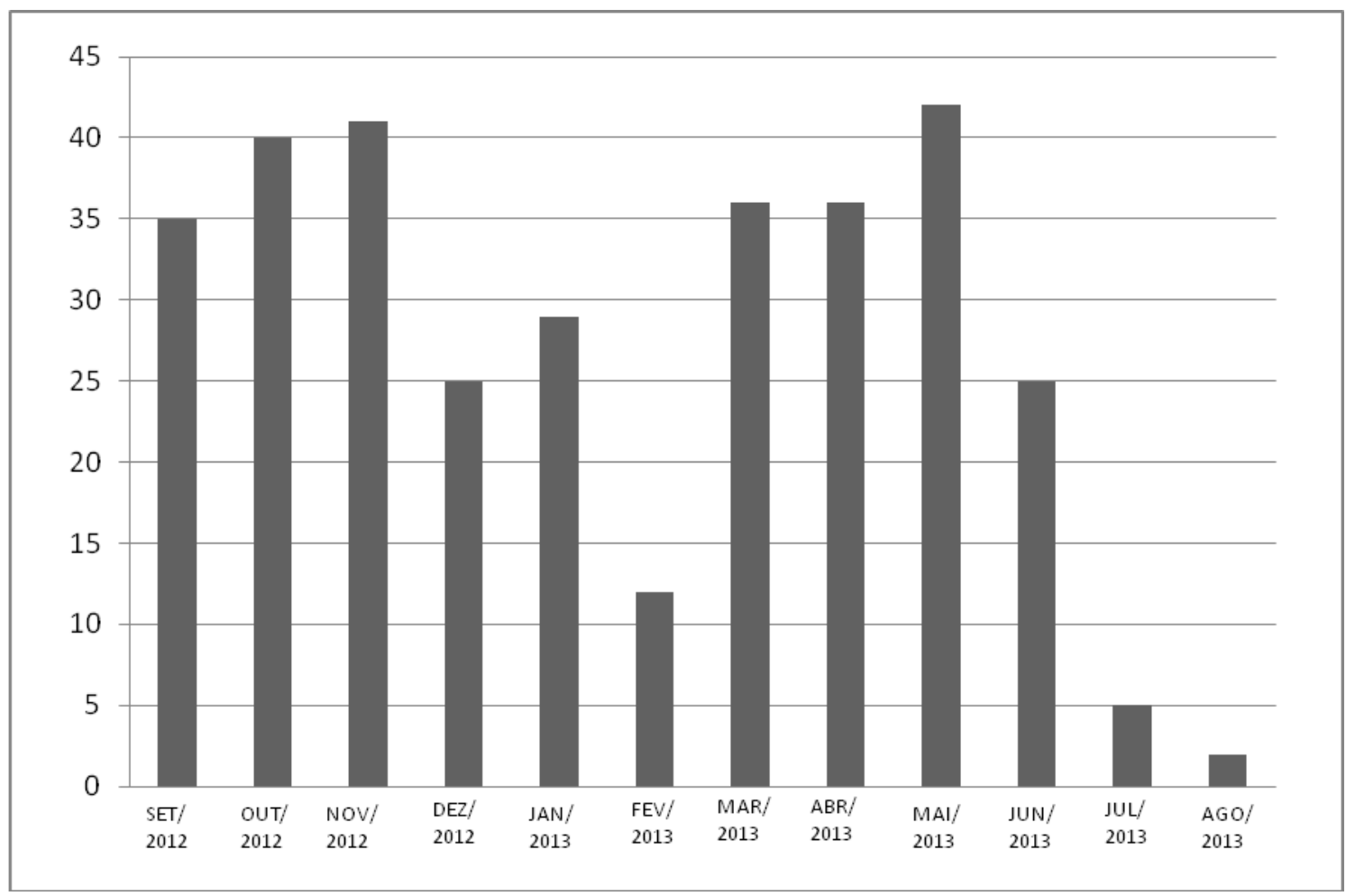

Figura 2. Distribuição das localizações da onça parda ao longo de 12 meses.

A área de vida de um animal é o espaço ou local onde ele desenvolve todas as suas atividades normais de forragear, acasalar e criar sua prole
(Burt, 1943). O resultado de um estudo de área de vida pode ser apresentado na forma numérica (em $\mathrm{km}^{2}$ ou hectare) e na forma geométrica de 
um polígono sobre um mapa da região onde foi realizado o estudo (Silveira, 2004). Devido às características espécie específicas, como: os hábitos solitários e o requerimento de grande volume alimentar, a onça parda costuma ocupar grandes áreas de vida, sendo registrado de 32 a $155 \mathrm{~km}^{2}$ no Pantanal Mato-Grossense (Crawshaw e Quiley, 1984) e até 144 a $317 \mathrm{~km}^{2}$ no deserto do Novo México (Logan e Sweanor, 2001).

Em região de remanescente de Mata Atlântica no Estado de São Paulo, Penteado (2012) obteve como área de vida de um espécime macho de onça parda aproximadamente $114 \mathrm{~km}^{2}$, utilizando 863 localizações obtidas em seis meses de monitoramento, também com a tecnologia GPS, porém por recuperação dos dados diretamente do radiocolar após sua recuperação. Os dados obtidos no presente trabalho sugerem que a área de uso do espécime monitorado seja de aproximadamente $610 \mathrm{~km}^{2}$, cerca de cinco vezes maior que o observado por Penteado (2012), também em bioma Mata Atlântica. Porém, não obstante a diferença metodológica, a principal característica em justificativa à grande diferença entre as áreas de uso observadas está relacionada à qualidade do habitat. Assim, enquanto Penteado (2012) refere-se a uma área de uso em região plana, com altitude média de $590 \mathrm{~m}$, englobando 2 rios de porte médio com presença de mata ciliar, a área de uso observada no presente trabalho apresenta grande variação de altitude $(500$ a $1500 \mathrm{~m})$, com característica extremamente acidentada e grande influência antrópica. O PESB é caracterizado por pressão de caça e presença de animais domésticos, como o cão; também foi registrada a presença e competição territorial por outros machos de onça parda na mesma área de estudo (Silva, 2013). Nesse sentido, os expostos associados à grande fragmentação da área de uso contribuem para a necessidade de uma área extrema para conseguir os recursos necessários à sua manutenção, sendo a área registrada, para esse animal, a maior área de vida já registrada para a espécie (Fig. 3).

Em $66,2 \%$ das localizações registradas, o animal se encontrava a uma altitude entre 1.000 a 1.499 metros, e em apenas $0,7 \%$ se encontrava a menos de 500 metros de altitude. Da mesma forma, como descrito por Penteado (2012), o registro das localizações geográficas do animal monitorado denota uma clara preferência por uso de áreas de remanescentes florestados. Assim, o comportamento de uso de áreas em maior altitude é provável reflexo da distribuição dos remanescentes de cobertura florestal original, os quais são poucos e situam-se nas regiões de grandes elevações, onde o relevo acidentado desencorajou a retirada da mata para uso do solo (Valverde, 1958; Costa, 2005; Netto e Diniz, 2010). Foi ainda possível o calculo das áreas de vida na estação chuvosa e na estação seca (Fig. 4). Durante a estação seca (abril a outubro), a área de uso calculada para o indivíduo foi de $604,83 \mathrm{Km}^{2}$; já na estação chuvosa (novembro a abril), foi de $542,92 \mathrm{~km}^{2}$. Esse comportamento provavelmente está relacionado à menor oferta de alimento na estação seca, forçando o animal a percorrer uma área maior para encontrar alimento.

O melhor expediente para preservar exemplares dos diversos ecossistemas, terrestres e aquáticos, bem como das comunidades bióticas das quais fazem parte, é a criação de reservas naturais (Shafer, 1990). Essas áreas são capazes de viabilizar os objetivos de conservação quando planejadas e manejadas como um todo (Milano, 1989). No entanto, um dado preocupante encontrado no presente estudo foi a baixa utilização da área do PESB pelo animal monitorado, apenas $20 \%$ da sua área de vida (Fig. 3). O animal monitorado utiliza principalmente pequenos fragmentos florestais isolados, próximos a propriedades rurais, e mesmo áreas urbanas; sua área de uso é ainda limitada pela presença da rodovia BR 262 a norte e BR 116 a leste. Nesse sentido, este e possivelmente outros indivíduos de onça parda na região do PESB encontram-se em grande vulnerabilidade às ações antrópicas, como a caça, atropelamentos e o contato com patógenos de animais domésticos. Porém o mais preocupante é o constante registro de casos de predação a animais domésticos, o que gera conflito direto com proprietários nem sempre sensíveis à causa conservacionista em vista ao prejuízo econômico. 
Aspectos do uso territorial...

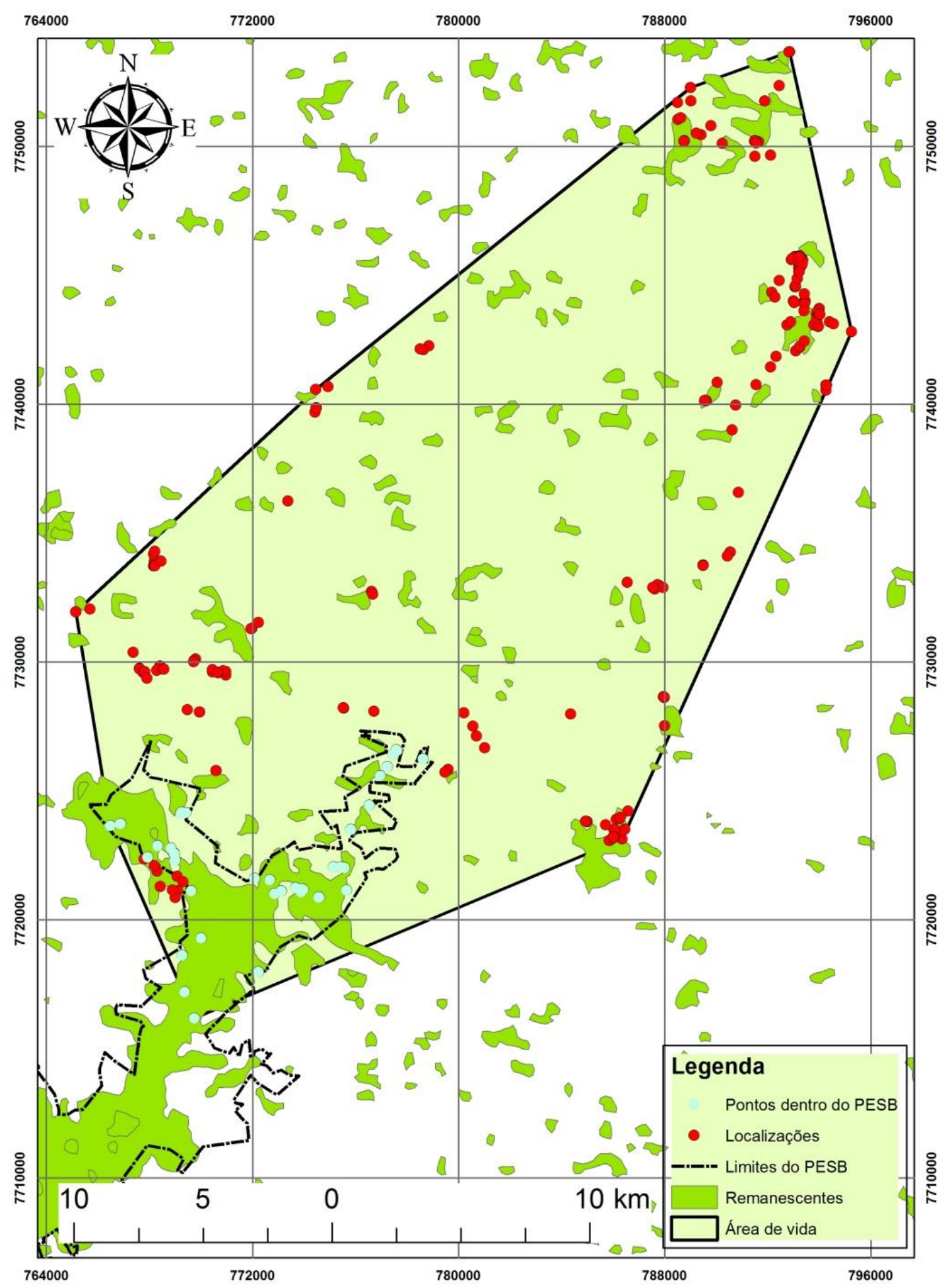

Figura 3. Área de uso de exemplar de Puma concolor monitorado por 12 meses na região do Parque Estadual Serra do Brigadeiro (PESB). 


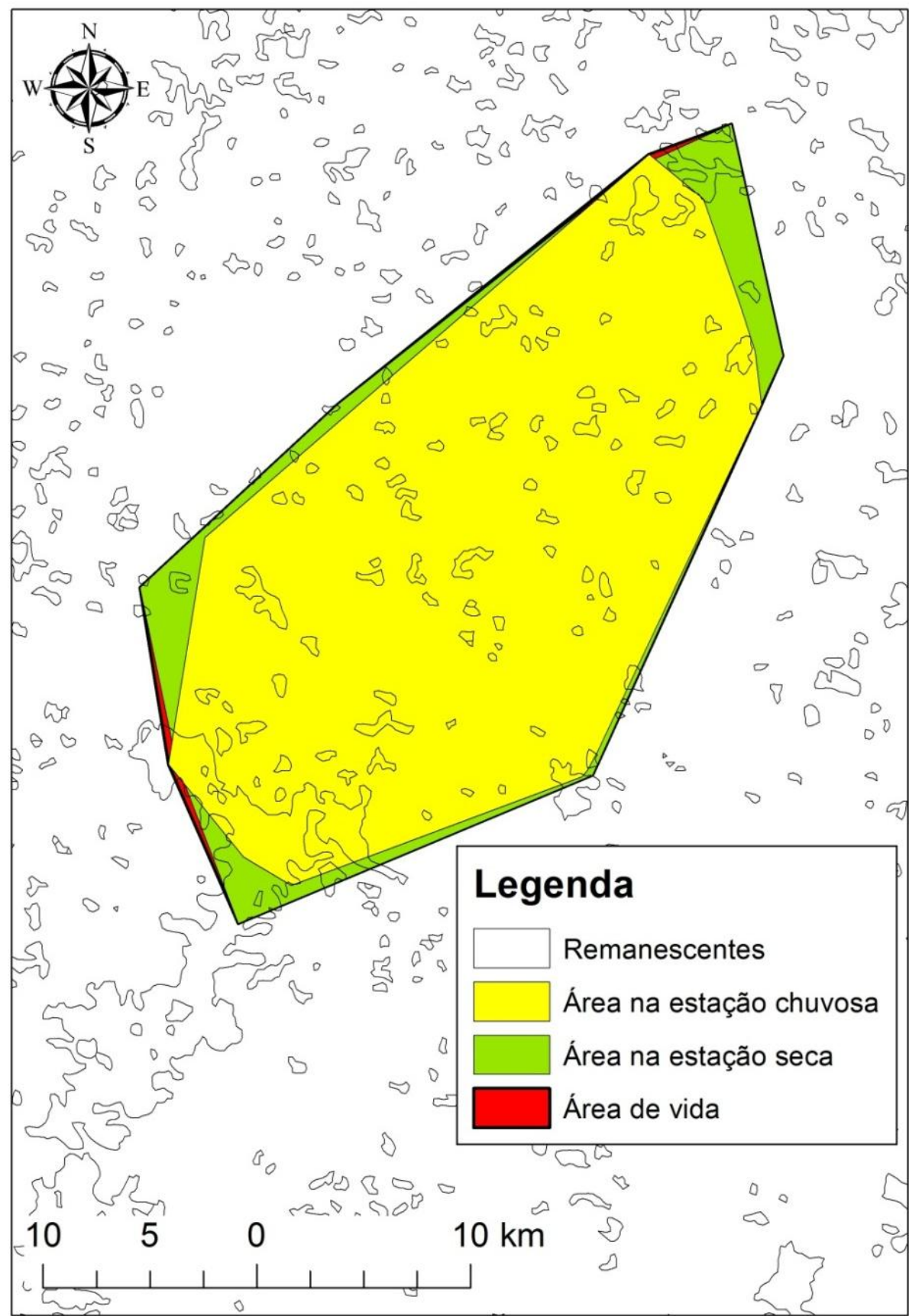

Figura 4. Área de vida da onça parda durante os 12 meses de estudo e nas estações seca e chuvosa.

O processo de criação de unidades de conservação, na maioria das vezes, resulta em sistemas de parques e reservas naturais altamente isolados ou apenas parcialmente representativos (Soulé e Terborgh, 1999). Essa situação é originada por inúmeras dificuldades na criação das UCs, tais como a ausência de estudos técnicos que abordem a seleção de áreas, ausência de fragmentos de grande tamanho em regiões altamente antropizadas e o valor econômico da terra (Gregorini, 2010). Dessa maneira, espécies com baixa densidade e grande área de vida, como observado no presente estudo, são as mais prejudicadas (Carvalho et al., 2009). Próximo ao PESB encontram-se duas reservas onde a onça parda também é encontrada, 
o Parque Estadual do Rio Doce (PERD) a norte e o Parque Nacional do Caparaó (PARNAC) a leste, ambas separadas do PESB por rodovias (BR 262 e 116, respectivamente); estas funcionando claramente como barreiras artificiais para o deslocamento do animal, uma vez que foram registradas localizações de até $1 \mathrm{Km}$ de distância destas sem a transposição. Nesse sentido o fluxo gênico entre essas áreas está atualmente restrito à adaptação individual e sobrevivência à transposição dessas barreiras.

Uma estratégia conservacionista de grande impacto seria a integração de diferentes Unidades de Conservação a partir da implementação de corredores ecológicos (Chetkiewicz et al., 2006), o que permitiria a dispersão e o fluxo gênico em populações restritas a fragmentos florestais (Sollman et al, 2008). O conceito de corredores ecológicos se baseia na reversão dos problemas gerados pela fragmentação, por meio da conexão de grandes fragmentos (normalmente protegidos na forma de UCs), através de fragmentos menores (Chetkiewicz et al., 2006). Essas ações de conservação estão dentro de uma escala de paisagem, que é considerada chave por representar a escala de movimento das espécies e para a discussão e execução de políticas públicas em conservação (Sanderson et al., 2002; Wikramanayake et al., 2002; Fortin e Agrawal, 2005).

\section{CONCLUSÃO}

O monitoramento territorial com telemetria de GPS via Satélite Globalstar mostrou-se eficiente em região de campos de altitude. O animal apresentou evidente preferência por locais florestados e a altas altitudes. A área de vida do animal foi a maior descrita para a espécie. A dispersão do indivíduo foi limitada por duas grandes rodovias que restringiram a continuidade da área de uso a outras unidades de conservação próximas ao PESB. Nesse sentido, corredores ecológicos interligando os parques (Parque Estadual da Serra do Brigadeiro, Parque Estadual do Rio Doce e Parque Nacional do Caparaó) podem ser considerados como estratégias de conservação para permitir o fluxo gênico da espécie na região.

\section{AGRADECIMENTOS}

À Fundação de Amparo à Pesquisa do Estado de Minas Gerais (FAPEMIG), ao Conselho Nacional de Desenvolvimento Científico e Tecnológico (CNPq) e à Rede Predadores de Topo de Cadeia (SISBIOTA/CNPq/FAPESP) pelos financiamentos da pesquisa. Ao Centro Nacional de Pesquisa e Conservação de Mamíferos Carnívoros (CENAP/ICMBio) e ao Instituto para a Conservação dos Carnívoros Neotropicais pelo apoio na realização da pesquisa.

\section{REFERÊNCIAS}

BANDEIRA DE MELO, L. Secret lives of maned wolves (Chrysocyon brachyurus Illiger, 1815): as revealed by GPS tracking collars. J. of Zoology, v.271, p.27-36, 2007

BIODIVERSITAS. Revisão das Listas das Espécies da Flora e da Fauna Ameaçadas de Extinção do Estado de Minas Gerais: Relatório Final, v.3. Belo Horizonte: Fundação Biodiversitas, 2007. 142p.

BURT, W.H. Territoriality and home range concepts as applied to mammals. J. fo Mammalogy, v.24, p.346352,1943

CARVALHO, A.F.; JUCKSCH, I.; VALENTE, O.F. Meio abiótico. In: FONTES, L.E. F.; OLIVEIRA, J.C.L.; GOMIDE, J.B. et al. Anais do Simpósio: Contribuições para Elaboração do Plano de Manejo Integrado e Participativo do PESB e Entorno. Universidade Federal de Viçosa, Viçosa. p.89-92, 2000.

CAUGHLEY, G.; SINCLAIR, A.R.E. Wildlife ecology and management. Blackwell Scientific Publications: Boston, 1994. 334p.

CHETKIEWICZ, C.L., CLAIR, C.C.S., BOYCE, M.S. Corridors for Conservation: Integrating Pattern and Process. Annu. Rev. Ecol. Evol. Syst., v.37, p.31742, 2006.

COSTA, T.C.C. Análise comparativa do meio físico e socioeconômico de três Municípios com parques florestais: Araponga, Caparaó e São Roque de Minas MG / Thomaz Corrêa e Castro da Costa e Liovando Marciano da Costa. - Rio de Janeiro : Embrapa Solos. $2005.42 \mathrm{p}$.

CRAWSHAW, P.G.; QUILEY, H.B. Estudos bioecológicos do Pantanal. A ecologia do jaguar ou onça pintada no Pantanal. Brasília: Instituto Brasileiro de Desenvolvimento Florestal,1984. 69p. 
DRUMMOND, G.M.; MARTIN, C.S.; MACHADO, A.B.M. et al. Biodiversidade em Minas Gerais. Um atlas para sua conservação. Belo Horizonte: Fundação Biodiversitas, 2005. 222p.

EIZIRIK, E.; KIM, J.H.; RAYMOND, M.M. et al. Phyogeography, population history and conservation genetics of jaguars (Panthera onca, Mammalia, Felidae). Mol. Ecology, v.10, p.65-79, 2001.

FORTIN, M.J., AGRAWAL, A.A. Landscape ecology comes of ages. Ecology,v.86 ,p.1965-1966, 2005.

GALETTI, M.; COSTA, C.; CAZETTA, E. Effects of forest fragmentation, anthropogenic edges and fruit color on the consumption of ornithochoric fruits. Biol. Conservation, v.111, p.269-293, 2003.

GREGORINI, M.Z. Distribuição da onça-pintada (Carnivora: Felidae) ao longo de uma paisagem antropizada: implicações para o manejo $e$ conservação da espécie. 2010. 93f. Dissertação de Mestrado. Universidade Federal de Goiás, Goiânia.

JACOB, A.A.; RUDRAN, R. Rádio telemetria em estudos populacionais. In: CULLEN Jr, L., VALLADARES-PADUA, C., RUDRAN, R. (Eds.). Métodos de estudo em biologia da conservação $e$ manejo da vida silvestre. Curitiba-PR: UFPR, 2003. $667 \mathrm{p}$.

LOGAN, K.A.; SWEANOR, L.L. Desert Puma: evolutionary ecology and conservation o an enduring carnivore. Washington, DC.: Island, 2001. 463p.

MILANO, M.S. Unidades de Conservação: conceitos e princípios de planejamento e gestão. Curitiba, FUPEF. 1989. 65p.

MOREIRA, G.F.; OLIVEIRA, F.S.; FRANÇA, M.M. et al. Estratificação ambiental numa topos sequência no Parque Estadual Da Serra Do Brigadeiro, MG. Cad. de Geografia, v.15, p.78-95, 2005.

NETTO, M.M.; DINIZ, A.M.A. Zona da mata de minas gerais, de espaço estratégico a região estagnada. In: Encontro de Pesquisadores da História da Zona da

PENTEADO, M.J.F. Áreas de vida, padrões de deslocamento e seleção de habitats por pumas (Puma concolor) e jaguatiricas (Leopardos pardalis), em paisagens fragmentadas de São Paulo. 2012. 139f. Tese de Doutorado. Instituto de Biologia, Universidade Estadual de Campinas, Campinas.

PINTO, L.P.; BEDÊ, L.; PAESE, A. et al. Mata Atlântica brasileira: os desafios para a conservação da biodiversidade de um hotspot mundial. In: ROCHA, C.F.D.; BERGALLO, H.G.; SLUYS, M.V.; ALVES, M.A.S. (eds.) Biologia e conservação: essências. São Carlos - SP: Rima Editora, 2006. 582p.

SANDERSON, E., REDFORD, K.H., CHETKIEWICZ, C. et al. Planning to save a species: the jaguar as a model. Conservation Biology; v.16, p.58-72, 2002.
SCOSS, L.M.; MARCO JÚNIOR, P.; SILVA, E.; MARTINS, S.V. Uso de parcelas de areia para o monitoramento de impacto de estradas sobre a riqueza de espécies de mamíferos. Rev. Árvore, v.28, p.121127, 2004

SHAFER, C.L. Nature Reserves: Island Theory and Conservation Practice. Smithsonian Institution Press, Washington, D.C., 1990. 189p.

SILVA, L.C. Estrutura da comunidade de mamíferos terrestres de médio e grande porte no Parque Estadual da Serra do Brigadeiro, MG. 2013. 61f. Dissertação de Mestrado, Universidade Federal de Viçosa, Viçosa.

SILVEIRA, L. Ecologia comparada e conservação da onça-pintada (Panthera onca) e onça-parda (Puma concolor), no Cerrado e Pantanal. 2004. 240f. Tese de Doutorado, Universidade de Brasília, Brasília.

SOISALO, M.; CAVALCANTI, S. Estimating the density of a jaguar population in the Brazilian Pantanal using camera traps and capture-recapture sampling in combinations with GPS radio-telemetry. Biol. Conservation, v.129, p.487-496, 2006.

SOLLMANN, R., TÔRRES, N,M, SILVEIRA, L. Jaguar conservation in Brazil: the role of protected areas. Cat News, Special Issue v.4, p.15-20, 2008.

SOULÉ, M.E.; TERBORGH, J. Continental Conservation: Scientific Foundations of Regional Reserve Networks. Island Press, Washington, D.C., 1999. 227p.

SUTHERLAND, W.J. The conservation handbook: research, management and policy. United Kingdom: Blackwell Science, 2000. p. 278.

VALVERDE, O. Estudo Regional da Zona da Mata de Minas Gerais. Rev. Bras. de Geografia. v.1, p.3-79, 1958.

VIANA, V.M.; TABANEZ, A.A.J. Biology and conservation of forest fragments in the Brazilian Atlantic moist forest. In: SCHELHAS, J., GREENBERG, R. Forest patches in tropical landscapes. Washington: Island Press, 1996. p. 151167.

WILDT, E.D.; BUSH, M.; GOODROWE, K.L. et al. Reproductive and genetic consequences of fouding isolated lion populations. Nature, v.329, p.328-331, 1987.

WIKRAMANAYAKE，E., DINERSTEIN，E., LOUCKS, C. et al. Ecoregions in Ascendance: Reply to Jepson and Whittaker. Conservation Biology, v.16, p.238-245, 2002. 